\title{
СТАТИСТИЧЕСКОЕ ИССЛЕДОВАНИЕ ВНЕШНЕТОРГОВЫХ ОПЕРАЦИЙ ПОСТСОВЕТСКИХ СТРАН В 1960-2016 ГГ.
}

\section{(c) 2020 Петров Александр Михайлович}

Департамент бизнес-аналитики, профессор, доктор экономических наук, доцент Финансовый университет при правительстве Российской Федерации, Россия, Москва E-mail: ampetrov@fa.ru.

\section{(c) 2020 Цыпин Александр Павлович}

Департамент бизнес-аналитики, доцент, кандидат экономических наук, доцент Финансовый университет при правительстве Российской Федерации, Россия, Москва

E-mail: zipin@yandex.ru

\section{(c) 2020 Стебунова Ольга Ивановна}

Кафедра информатики и вычислительной техники пищевых производств, доцент, кандидат экономических наук, доцент

Московский государственный университет пищевых производств, Россия, Москва

E-mail: stebunovaoi@mgupp.ru.

Распад Советского Союза и последовавшие за этим дезинтеграционные и интеграционные процессы на постсоветском пространстве ставят перед экономической наукой задачу изучения новых явлений, процессов, объектов. К таковым можно отнести формирование внешнеэкономических взаимоотношений между постсоветскими странами и мировым сообществом. В этом направлении количественный анализ, с применением статистического инструментария, играет немаловажную роль. В этой связи можно сформулировать цель проведения исследования, которая заключается в выявлении сложившихся закономерностей в структуре и динамике показателей внешней торговли постсоветских стран за длительный период времени. Для достижения поставленной цели были использованы такие статистические методы как: графический, табличный, абсолютных и относительных величин. В качестве основных результатов исследования можно назвать: проанализирована динамика внешнеторговых операций постсоветских стран в двух периодах развития, выявлены траектории движения экспорта-импорта и доказано влияние на волатильность показателей экономико-политических кризисов; проведен сравнительный анализ структуры экспорта (импорта) постсоветских стран по товарным направлениям и географии внешнеэкономических партнеров. Полученные в ходе работы выводы будут полезны исследователям в области переходной экономики постсоветских стран, а также служащим государственных учреждений для формирования политики интеграции России и стран постсоветского пространства.

Ключевые слова: статистика, внешнеэкономическая деятельность, экспорт, импорт, динамика, структура, постсоветские страны.

\section{Введение}

Неотъемлемой частью экономики страны являются внешнеторговые операции, посредством которых осуществляется приток в страну необходимых товаров (работ, услуг) и реализуются на мировом рынке продукция внутреннего производства. Для России и ряда постсоветских стран внешнеэкономическая деятельность также является источником пополнения консолидированного бюджета в виде налогов и таможенных сборов от продажи углеводородов. Проводя анализ товаропотоков, можно выявить направленность промышленного производства (мировое разделение труда) и дисбаланс в экономической структуре страны. Рассматриваемое направление анализа особенно актуально в постсоветских странах, так как распад Советского Союза разрушил все внешнеэкономические связи, в результате вновь образованные республики вынуждены с нуля выстраивать экономические взаимоотношения с внешним миром. Также нужно выделить особенность, присущую рассматриваемой совокупности стран, которая заключающаяся в развитии такого направления как взаимная торговля, т.е. торговля на особых условиях между членами интеграционных 
международных союзов (к примеру, СНГ, ЕАЭС, ШОС). Резюмируя вышесказанное можно заключить, что количественное изучение динамики и структуры внешнеторговых операций постсоветских стран является актуальной задачей для экономической науки, в общем, и статистической науки в частности.

Актуальность разрабатываемой темы подчеркивается в трудах отечественных ученых, среди которых можно выделить таких как Гладков И.С. [2] и Чернов Н.А. [10], данные исследователи обращались к проблематике внешнеэкономической деятельности в общем по совокупности постсоветских стран, в свою очередь экспортно-импортные операции по отдельным странам и(или) политико-экономическим союзам нашли отражение в работах таких авторов как Андреев А. В. [1], Егорова М. Л. [3], Каукин А. [4], Кизяева А. М. [5], Килин В. В. [6], Подбиралина Г. В. [7], Троекурова И. С. [9].

Обобщая накопленный отечественный опыт в области анализа внешнеэкономической деятельности России и прочих постсоветских стран, можно сделать вывод об объективной необходимости углубленного рассмотрения выделенного направления с применением статистического инструментария к экспортно-импортным операциям с целью выявления закономерностей присущих странам постсоветского пространства.

\section{Методы}

В проводимом нами исследовании используются такие статистические методы как - табличный и графический, абсолютных и относительных величин, некоторые эконометрические методы.

Показатели, используемые в настоящем исследовании (к примеру, товарооборот, экспорт, импорт и т.д.), характеризующие внешнеэкономическую деятельность государств, представляют собой стоимостные величины, это накладывает ограничения на ряд подходов к их анализу, в частности невозможно сформировать временной ряд экспорта-импорта за длительный период, так как товаропоток измерен в несопоставимых валютах. В этой связи будем рассматривать отдельно два периода, до и после 1990 года, сравнение между советским и постсоветским периодом будем проводить на основе относительных величин.

В качестве источников информации используем: для характеристики тенденций в советский период сведения из официального статистического ежегодника серии «Внешние экономические связи СССР», для отображения текущей ситуации внешней торговли постсоветских стран используем сведения данные Bсемирного Банка, а также данные содержащиеся в сборнике «International Trade Statistics Yearbook» публикуемый Статистическим отделом ООН. Данное издание выпускается с начала 1990-х годов в двух томах. Том I - содержит информацию по экспорту-импорту стран мира, как в динамике, так и в структуре. Том II - содержит сведения о международной торговле различными товарами.

\section{Результаты}

Отправной точкой анализа изменений происходящих в внешнеэкономических связях постсоветских стран выберем 1960 год, динамика внешнеторгового оборота с данного периода до 1990 года представлена на рисунке 1.

Как следует из представленной на рисунке 1 информации, товарооборот резко увеличился в середине 1970-х годов, но при этом экспорт замедлил свой рост, а импорт наоборот увеличил.

В начале рассматриваемого периода основные товаропотки протекали между СССР и странами-членами СЭВ, так в 1970 г. доля оборота составляла 55,6\%, в 1980 г.-53,2\%, а в 1990 г. снизилась до 43,8\%. Тогда как торговля с промышленно развитыми капиталистическими странами только увеличивалась и на момент отчетного период составляла 38,0\%. Получаем, что с течением времени произошла смена направления торговли, что в общем укладывается в логические объяснения, так развитые страны охотно покупали из союза товары сырьевой направленности, в свою очередь СССР ввозил высокотехнологичные товары, которые страны СЭВ не могли предложить.

На этом фоне показательна структура контрагентов Советского Союза по внешнеэкономической деятельности. Если в 1960 г. все крупные партнеры были из Совета экономической взаимопомощи (ГДР - 18\% от всего оборота ВЭД, Чехословакия - 11\%, Китай - 15\%, Польша - 8\%, Болгария - 6\%, Венгрия - 5\%), то по итогам 1990 года к странам СЭВ присоединились европейские страны (Объединенная Германия - 15\%, Чехословакия - 9\%, Польша - 9\%, Болгария - 9\%, Венгрия - 6\%, Финляндия - 3\%, Италия - 3\%). Также стоит указать, что доля экспорта и импорта между СССР и выделенными странами была примерно одинаковой, но вот структура ввози- 


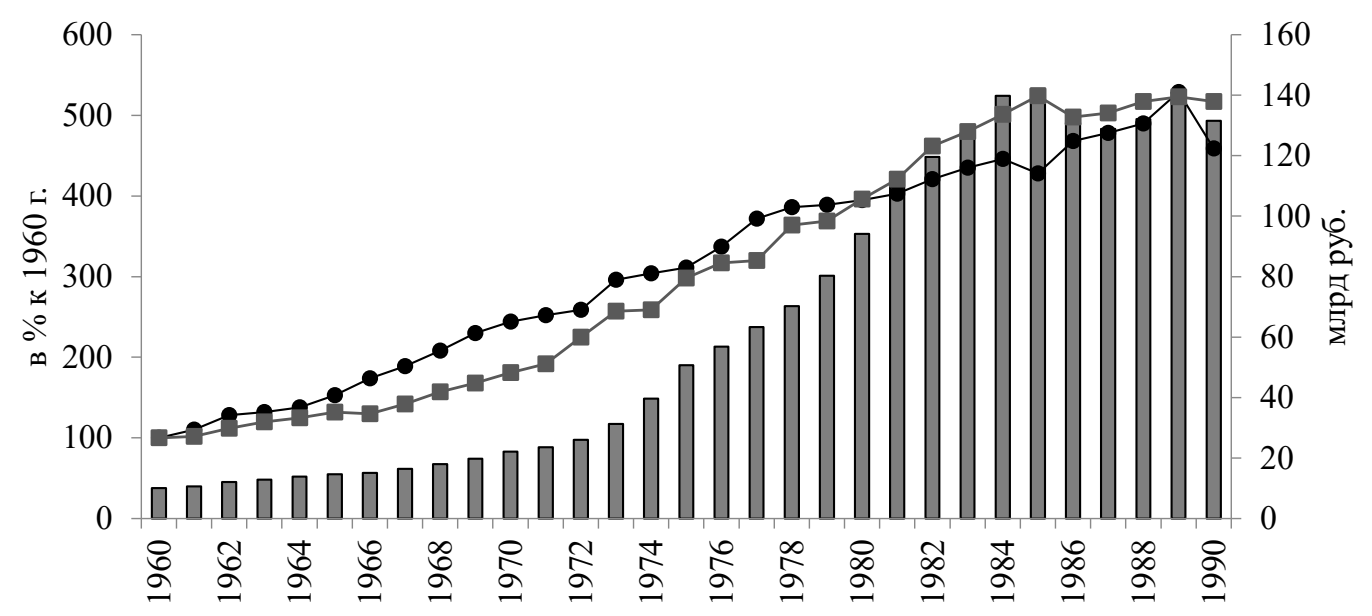

$\square$ Оборот внешней торговли СССР (в ценах соответствующих лет), млрд руб.

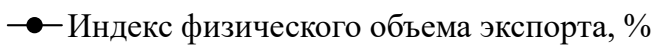

- - Индекс физического объема импорта, \%

Puc. 1. Динамика экспорта-импорта СССР (Источник: составлено авторами на основе статистического ежегодника серии «Внешние экономические связи СССР»)

мых и вывозимых товаров разная (таблица 1).

Представленные в таблице 1 сведения показываю, что в отчетном году наибольшая доля в экспорте это категория «топливо и энергетика» (40,5\%), но в 1970 г. доля была значительно ниже, всего $18,0 \%$, т.е. начиная с 1980 -х годов наблюдается изменение структуры в сторону увеличения объемов углеводородов. В свою очередь наибольший удельный вес в импорте составляет категория «машины, оборудование и транспортные средства», т.е. подтверждается сделанное выше предположение о нехватке в союзе высокотехнологичных товаров.

Далее обратимся к периоду 1990-2016 гг. и проследим, как изменилась динамика и структура показателей характеризующих внешнюю торговлю постсоветских стран под влиянием трансформационного перехода к рыночной экономике.

Согласно данных представленных в таблице 2, для всех постсоветских стран характерно низкое значение экспорта (импорта) в 1990 году и резкий рост к 2000 году, в дальнейшем значение показателя стабилизируется [9]. Данная закономерность объясняется некоторым замешательством в связи с поиском странами своей ниши на международном рынке и налаживание новых (восстановление прежних) внешнеэкономических связей.

Самый большие показатели экспорта (по оношению к ВВП) наблюдаются в таблице 2 по Эстонии $-79,0 \%$, также эта страна явлется лидером и в импорте $-75,1 \%$. Что касатся России, то значения рассмариваемого показателя у данной стра-

Таблица 1. Наиболее весомые товарные группы в структуре экспорта-импорта СССР, \%

\begin{tabular}{|l|c|c|c|c|c|c|}
\hline \multirow{2}{*}{ Товарные группы } & \multicolumn{3}{c|}{ Экспорт,\% } & \multicolumn{3}{c|}{ Импорт,\% } \\
\cline { 2 - 7 } & 1970 г. & 1980 г. & 1990 г. & 1970 г. & 1980 г. & 1990 г. \\
\hline машины, оборудование и транспортные средства & 21,8 & 15,8 & 18,3 & 35,5 & 33,9 & 44,8 \\
\hline топливо и электроэнергия & 18,0 & 46,9 & 40,5 & 2,0 & 3,0 & 2,6 \\
\hline руды и концентраты, металлы и изделия из них & 18,7 & 8,8 & 11,3 & 9,6 & 10,8 & 5,1 \\
\hline химические продукты, удобрения и каучук & 3,4 & 3,3 & 4,6 & 5,7 & 5,3 & 4,1 \\
\hline лесоматериалы и целлюлозно-бумажные изделия & 6,3 & 4,1 & 3,7 & 2,1 & 2,0 & 1,0 \\
\hline текстильное сырые и полуфабрикаты & 3,3 & 1,9 & 1,2 & 4,8 & 2,2 & 1,1 \\
\hline пищевкусовые товары и сырые для их производства & 9,2 & 1,9 & 2,0 & 15,8 & 24,2 & 15,8 \\
\hline промышленные товары народного потребления & 2,9 & 2,5 & 3,6 & 18,3 & 12,1 & 17,7 \\
\hline
\end{tabular}

Источник: составлено авторами на основе статистического ежегодника серии «Внешние экономические связи СССР» 
ны самые низкие по импорту (20,5\%) и одни из самых низких (на третьем месте) по экспорту, что объясняется внушительными размерами ВВП этого государства.

Если же обратится к удельным весам постсоветских стран в общем объеме товарооборота то Россия занимает первую позицию, так в 1990 г. ее доля в экспорте составляла $63 \%$, в импорте $56 \%$, в отчетном периоде $56 \%$ и $49 \%$ соответственно.
С целью проведения сопоставления развития рассматриваемых явлений до и после 1991 года рассчитаем индекс физического объема экспорта (импорта) к 1990 году по каждой постсоветской стране и найдем среднюю геометрическую, результаты представим на рисунке 2 .

Как и в предшествующий, советский период развития, наблюдается рост экспорта (импорта), но также стоит выделить участок ряда

Таблица 2. Изменение экспорта и импорта в постсоветских странах, в \% ВВП

\begin{tabular}{|c|c|c|c|c|c|c|c|c|}
\hline \multirow{2}{*}{ Страны } & \multicolumn{4}{|c|}{ Экспорт, в\% ВВП } & \multicolumn{4}{c|}{ Импорт, в\% к ВВП } \\
\cline { 2 - 9 } & 1990 г. & 2000 г. & 2010 г. & 2016 г. & 1990 г. & 2000 г. & 2010 г. & 2016 г. \\
\hline RUS & 18,2 & 44,1 & 29,2 & 25,7 & 17,9 & 24,0 & 21,1 & 20,5 \\
\hline UKR & 27,6 & 62,4 & 47,1 & 49,3 & 28,7 & 57,4 & 51,1 & 55,5 \\
\hline BLR & 46,0 & 69,2 & 51,4 & 62,5 & 43,7 & 72,4 & 64,6 & 62,7 \\
\hline UZB & 28,8 & 24,6 & 31,7 & 18,9 & 47,8 & 21,5 & 28,5 & 20,7 \\
\hline KAZ & 7,8 & 56,6 & 44,2 & 31,8 & 30,5 & 49,1 & 29,9 & 28,5 \\
\hline GEO & 40,0 & 23,0 & 35,0 & 43,6 & 45,3 & 39,7 & 52,8 & 59,3 \\
\hline AZE & 43,9 & 39,0 & 54,3 & 46,4 & 39,2 & 38,4 & 20,7 & 43,7 \\
\hline LTU & 38,7 & 38,5 & 65,3 & 74,5 & 47,4 & 44,7 & 67,2 & 73,2 \\
\hline MDA & 48,7 & 49,8 & 39,2 & 43,3 & 51,0 & 75,4 & 78,6 & 71,3 \\
\hline LVA & 39,4 & 36,9 & 53,7 & 60,0 & 43,5 & 44,9 & 55,1 & 59,2 \\
\hline KGZ & 29,2 & 41,8 & 51,6 & 35,8 & 49,6 & 47,6 & 81,7 & 70,0 \\
\hline TJK & 27,8 & 98,8 & 14,9 & 13,3 & 35,1 & 100,9 & 58,6 & 42,8 \\
\hline ARM & 35,0 & 23,4 & 20,8 & 33,1 & 46,3 & 50,5 & 45,3 & 42,8 \\
\hline TKM & 111,2 & 97,2 & 76,3 & 74,4 & 107,5 & 82,4 & 44,5 & 44,1 \\
\hline EST & 42,0 & 61,6 & 75,1 & 79,0 & 49,9 & 64,9 & 68,7 & 75,1 \\
\hline
\end{tabular}

Источник: составлено авторами на основе сведений Статистического отдела ООН и данных Всемирного банка

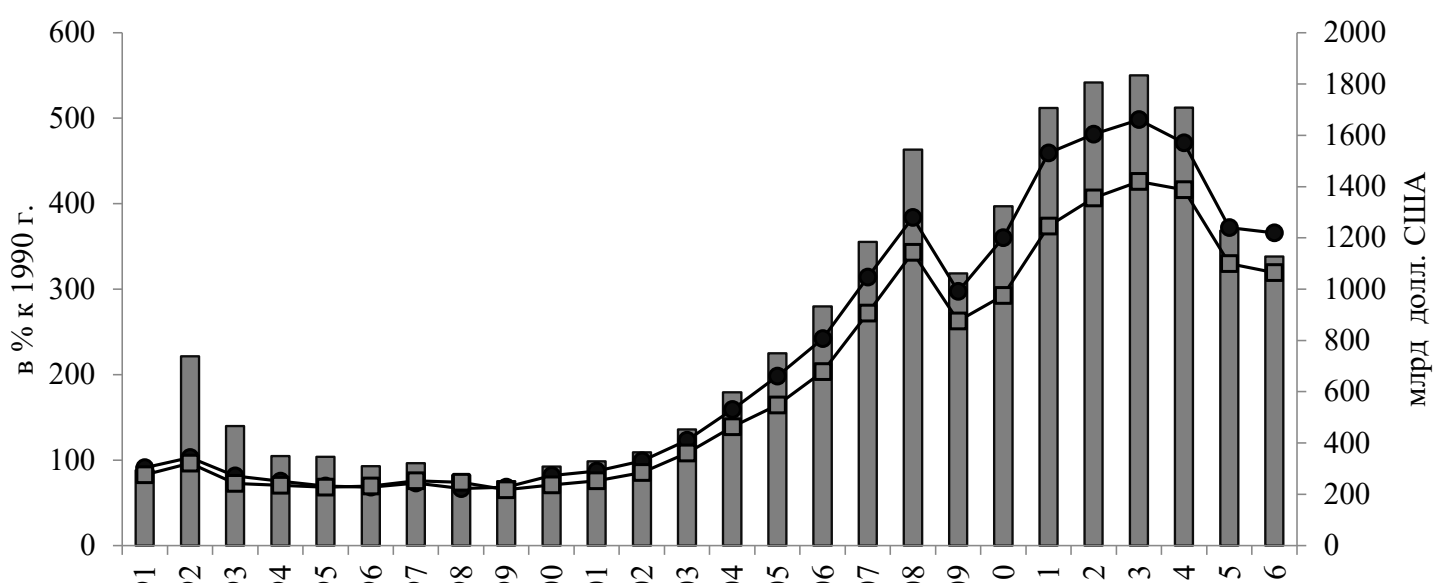

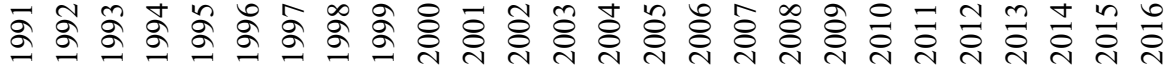

$\square$ Оборот внешней торговли постсоветских стран, млрд долл. США

- -Индекс физического объема экспорта, \%

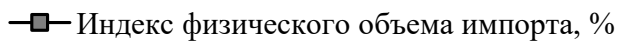

Puc. 2. Динамика экспорта-импорта постсоветских стран

(Источник: составлено авторами на основе данных Статистического отдела ООН) 
1991-2003 гг. когда имеем снижение относительно 1990 г., далее резкий рост. Обнаруженная закономерность объясняется общим трансформационным спадом присущим всем постсоветским странам. Также явно выделяются провалы в 2009 г. и 2015-2016 гг., что объясняется влиянием кризисов, более отчетливо данная закономерность проявляется на рисунке 3.

Формализовать выдвинутую мысль о влиянии кризисных ситуаций на динамику экспортаимпорта постсоветских стран поможет тест Чоу. Для его проведения выделим 1993 г., 1998 г., 2009 г., 2015 г. Для ряда экспорта получаем фактическое значение F-критерия Фишера равное 3,78 (при р-уровне 0,01 ), для импорта $\mathrm{F}_{\text {факт }}=4,30$ (при р-уровне 0,01), таким образом, тест доказывает наличие точек выделяющихся из общей траектории движения временных рядов, т.е. кризисы оказывают существенное влияние на внешнеэкономическую деятельность постсоветских стран.

Так как Россия вносит наибольший вклад, как в экспорт, так и в импорт, то рассмотрим, кто является ее контрагентами по ВЭД. Так в 1990 году на долю экспорта со странами СНГ приходилось 2,5\% всего оборота (импорт $-2,2 \%$ ), соответственно удельный вес экспорта со странами дальнего зарубежья равен 97,5\% (импорт 98,8\%). В 2016 году расстановка весов немного изменилась экспорт с первой категорией стран вырос до 13,2\% (импорт - 10,7\%), на вторую категорию контрагентов пришлось $86,8 \%$ экспорта (импорт - 89,3\%).
Что касается географической направленности внешнеэкономической деятельности, то в 2016 году основными контрагентами России по экспорту были: Нидерланды (10,2\%), Китай (9,8\%), Германия (7,4\%), Беларусь (5,0\%), Турция $(4,8 \%)$. Импорт поставлялся в РФ из таких стран как: Китай (20,9\%), Германия (10,7\%), США (5,9\%), Беларусь (5,3\%), Франция (4,7\%), Япония (3,7\%).

Получаем, что Германия по прежнему остается одним из крупнейших партнеров России по внешнеторговому обороту, также значительный вклад вносит Беларусь, но самым важным партнером является Китай, который поставляет на внутренний рынок РФ высокотехнологичные товары.

Далее обратимся к анализу сведений содержащихся в статистическом ежегоднике «International Trade Statistics Yearbook», сразу заметим, что за 2015-2016 гг. опубликованы сведения по 12 постсоветским республикам, данные по Узбекистану, Туркменистану и Таджикистану получим от официальных национальных статистических служб.

Структура экспорта и импорта анализируемых стран разбита в соответствии со Стандартной международной торговой классификацией (Standard International Trade Classification SITC), которая разрабатывается Статистической комиссией $\mathrm{OOH}$ (таблица 3).

Согласно данных представленных в таблице 3, экспорт России, Беларуси, Казахстана, Азербайджана это углеводороды и производные из них, получаем, что заложенная в СССР в 1980-х

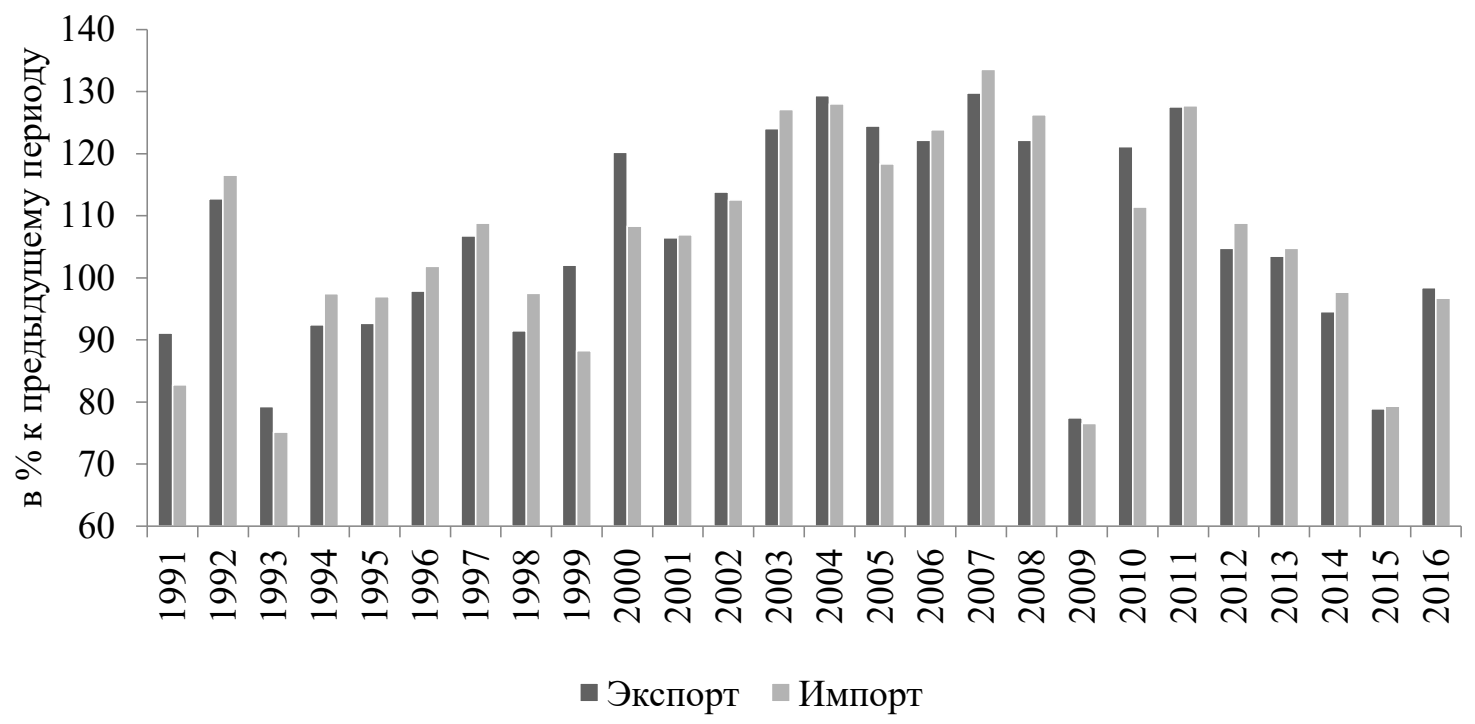

Puc. 3 Динамика экспорта-импорта товаров и услуг, в\% к предыдущему периоду (Источник: составлено авторами на основе данных Статистического отдела ООН) 
Таблица 3. Наибольшая доля экспорта (импорта) в структуре SITC в разрезе постсоветских стран в 2016 году

\begin{tabular}{|c|c|c|c|c|c|c|c|}
\hline Страна & $\begin{array}{c}\text { Направле- } \\
\text { ние }\end{array}$ & Код SITC & $\begin{array}{c}\text { Доля кате- } \\
\text { гории, \% }\end{array}$ & Страна & $\begin{array}{c}\text { Направле- } \\
\text { ние }\end{array}$ & Код SITC & $\begin{array}{c}\text { Доля кате- } \\
\text { гории, \% }\end{array}$ \\
\hline \multirow{2}{*}{ RUS } & экспорт & 3 & 47,2 & \multirow{2}{*}{ LTU } & экспорт & 7 & 18,5 \\
\hline & импорт & 7 & 41,2 & & импорт & 7 & 26,0 \\
\hline \multirow{2}{*}{ UKR } & экспорт & 6 & 28,4 & \multirow{2}{*}{ MDA } & экспорт & $0+1$ & 32,8 \\
\hline & импорт & 3 & 29,0 & & импорт & 7 & 21,6 \\
\hline \multirow{2}{*}{ BLR } & экспорт & 3 & 20,8 & \multirow{2}{*}{ LVA } & экспорт & 7 & 22,3 \\
\hline & импорт & 3 & 26,8 & & импорт & 7 & 27,9 \\
\hline \multirow{2}{*}{ KAZ } & экспорт & 3 & 50,7 & \multirow{2}{*}{ KGZ } & экспорт & 9 & 54,1 \\
\hline & импорт & 7 & 34,8 & & импорт & 6 & 20,7 \\
\hline \multirow{2}{*}{ GEO } & экспорт & $0+1$ & 32,0 & \multirow{2}{*}{ ARM } & экспорт & $0+1$ & 28,7 \\
\hline & импорт & 7 & 28,8 & & импорт & 6 & 19,8 \\
\hline \multirow{2}{*}{ AZE } & экспорт & 3 & 87,2 & \multirow{2}{*}{ EST } & экспорт & 7 & 32,3 \\
\hline & импорт & 7 & 34,6 & & импорт & 7 & 32,9 \\
\hline
\end{tabular}

Источник: составлено авторами на основе ежегодника «International Trade Statistics Yearbook». Примечание: коды в соответствии с SITC: 0 Продукты питания и живые животные + 1 Напитки и табак; 3 Минеральные топлива, смазки и аналогичные материалы; 6 Промышленные товары, классифицируемые в основном по материалу; 7 Машины и транспортное оборудование; 9 Прочие товары и сделки, не вошедшие в другие группы SITC.

годах структура экспорта была унаследована этими странами.

Такие страны как Армения, Грузия и Молдова не обладают значительными запасами полезных ископаемых, поэтому основными товарами, идущими на экспорт у этих стран, является продукция сельскохозяйственного производства.

Страны, вошедшие в Европейский союз (Латвия, Литва и Эстония) экспортируют (импортируют) машины и транспортное оборудование, данная закономерность объясняется транзитными потоками, проходящими через эти страны из Центральной Европы в Восточную Европу и Азию.

Наследие Советского Союза прослеживается и в импорте постсоветских стран, так согласно таблице 1 наибольшая доля импорта приходилось на машины и оборудования, согласно данных таблицы 3 аналогичная картина прослеживается в большинстве представленных стран. T.е. за прошедшие четверть века республикам не удалось наладить внутреннее производство высокотехнологичных машин, оборудования и транспортных средств.

Далее остановимся на внешнеэкономической деятельности стран не вошедших в ежегодник «International Trade Statistics Yearbook», так в Узбекистане в 2016 году удельный вес экспорта во внешней торговле стран СНГ составил 34,8\% (импорта 33,4\%), прочих стран мира - 65,2\% (импорта 66,6\%). Основными партнерами яв- ляются Афганистан, Иран, Казахстан, Китай, Республика Корея, РФ, Турция. Наибольший удельный вес в экспорте в 2016 году приходился на такие категории как «энергоносители и нефтепродукты» - 14,2\% и «услуги» - 25,8\%. Соответственно доминирующие позиции в импорте занимали «химическая продукция и изделия из нее» - 17,5\% и «машины и оборудование» - 41,3\%. Получаем, что сложившаяся структура внешнеторгового оборота Узбекистана, в общем, согласуется со сложившейся закономерностью по совокупности постсоветских стран.

Внешнеторговый оборот Таджикистана в 2016 году на 50,1\% составляли сделки со странами СНГ и на 49,9\% с остальными странами мира. Основными контрагентами являются Германия, Казахстан, РФ, Туркменистан, Турция, Швейцария. При этом 32,5\% всего импорта идет из России. В товарной структуре импорта выделяются две крупные категории «волокно хлопковое»13,6\% и «руды и концентраты» - 26,6\%. В свою очередь наибольшей долей в импорте обладают такие категории как «пшеница» - 7,6\% и «нефтепродукты» - 8,6\%. В общем, товарная структура экспорта-импорта не выбивается из общей закономерности сложившееся по совокупности стран экс-членов СССР.

Прежде чем перейти к рассмотрению величины показателей по Туркменистану, стоит отметить, что информации по данной республике 
крайне мало, на сайте официального Государственный комитет Туркменистана по статистике представлено всего несколько макроэкономических показателей, остальная информация по стране не доступна (отсутствует). Скудные и обрывочные сведения позволяют с определенной долей вероятности утверждать, что основными товарами Туркменистана, идущими на экспорт, являются углеводороды: «газы нефтяные» (более 70\%) и «нефтепродукты» (около 10\%), соответственно импорт представлен такими категориями как «сырье и материалы» (около 35\%), «технологическое оборудование и механические приспособления» (чуть более 30\%), «транспортные средства» (менее 10\%) и «потребительские товары» (около 20\%). Основными контрагентами республики на мировом рынке являются: Германия, Италия, Китай, Россия, Турция, Украина.

Резюмируя итоги анализа товарной структуры экспорта-импорта Узбекистана, Таджикистана и Туркменистана, можно утверждать, что заложенная в Советском Союзе структуры внешнеторговых операций остается актуальной для выделенных стран.

\section{Заключение}

Подводя тоги проведенного статистического анализа динамики и структуры внешнеторговых операций пятнадцати постсоветских стран можно сформулировать выводы представленные ниже.

1. Анализ динамики экспорта-импорта на двух участках развития показал, что в советский период наблюдается непрерывный рост относительно 1960 года, в свою очередь в постсоветский период наблюдаем значительный провал относительно 1990 года, который про- должался вплоть до середины 2000-х годов. Выявленная закономерность объясняется общим трансформационным спадом и разрывам всех международных связей, т.е. новым республикам понадобилось время для формирования пула контрагентов ВЭД и спектра товаров поставляемых на внешний рынок.

2. Товарная структура экспортно-импортных операций осуществляемых советским союзом характеризуется высоким удельным весом вывозимых полезных ископаемых (в основном углеводороды) и доминированием на ввозе категории «машины, оборудование и транспортные средства». Прошедшие четверть века рыночных преобразований в постсоветских странах в значительной мере не изменил сложившуюся структуру, так страны богатые полезными ископаемыми осуществляют их экспорт, а страны не имеющие таковых торгуют продовольственными товарами, но практически все республики вошедшие в анализируемую совокупность осуществляют импорт высокотехнологичного товаpa.

3. География товарооборота с момента распада СССР претерпела незначительные изменения, так к устоявшимся во времени партнерским отношениям добавились такие направления как Китай, страны Персидского залива, страны Еврозоны, а также значителен объем экспортно-импортных операций между постсоветскими странами, в некоторых республиках превышающий 50\%. Высокий уровень взаимной торговли объясняется тесными социально-экономическими связями, а также формировании на постсоветском пространстве ряда экономико-политических союзов (СНГ, Таможенный союз, ЕАЭС, ШОС и т.д.).

\section{Библиографический список}

1. Андреев А. В. Развитие внешней торговли стран Содружества независимых государств: итоги 2010 г. // Российский внешнеэкономический вестник. - 2011. - № 9.- С. 110-115.

2. Гладков И. С. Внешнеторговые связи на постсоветском пространстве: тенденции XXI в. // Власть. - 2016. - T. 24.- № 4.- С. 52-61.

3. Егорова М.Л. Тенденции развития взаимной и внешней торговли стран ЕАЭС // Новая наука: От идеи к результату. - 2016. - № 5-1 (84).- С. 59-62.

4. Каукин А., Идрисов Г. Гравитационная модель внешней торговли России: случай большой по площади страны с протяженной границей // Экономическая политика.-2013. - № 4.- С. 133-154.

5. Кизяева А.М., Ходоровский Е. П. Специфика внешней торговли таможенного союза ЕВРАЗЭС в условиях расширения интеграции // Актуальные проблемы науки и практики современного общества. - 2016. - № 2 (2). - C. $42-45$. 
6. Килин В. В. Евразийская экономическая интеграция: внешнеторговые и экономические аспекты // Диалог: политика, право, экономика.-2016. - № 1.-С. 65-72.

7. Подбиралина Г.В. Основные направления внешнеторгового сотрудничества стран Евразийского экономического союза // Международная торговля и торговая политика._-2016. - № 1 (5). - С. 15-26.

8. Попов В.В., Цыпин А. П. Количественная оценка влияния изменения структуры экспортно-импортных товаропотоков на основные макроэкономические показатели России // Экономика и предпринимательство.2015. - № 9-2 (62). - С. 314-319.

9. Троекурова И.С., Пелевина К.А. Гравитационные модели внешней торговли стран БРИКС // Известия Саратовского университета. Новая серия. Серия: Экономика. Управление. Право.- 2014.- Т. 14.- № 1-2.- С. 133-142.

10. Чернов Н.А. Анализ внешней торговли постсоветских стран: гравитационный метод // Вестник Университета (Государственный университет управления). - 2017. - № 6.- С. 92-99. 